\title{
Phenotypic variation of floral organs in flowering crabapples and its taxonomic significance
}

\author{
Ting Zhou' ${ }^{1}$, Kun Ning ${ }^{2}$, Wangxiang Zhang ${ }^{3 *}$, Hong Chen ${ }^{1}$, Xiaoqing Lu', Donglin Zhang ${ }^{4}$, \\ Yousry A. El-Kassaby and Jian Bian ${ }^{6}$
}

\begin{abstract}
Background: In angiosperms, phenotypic variation of floral organs is often considered as the traditional basis for the evolutionary relationship of different taxonomic groups above the species level. However, little is known about that at or below the species level. Here, we experimentally tested the phenotypic variation of Malus floral organs using combined methods of intraspecific uniformity test, interspecific distinctness analysis, principal component analysis, Pearson correlation analysis, and Q-type cluster analysis. The ancestor-inclined distribution characteristic analysis of Malus species and cultivars floral attributes was also carried out, so as to explore its taxonomic significance.

Results: 15/44 phenotypic traits (e.g., flower shape, flower type, flower diameter, ...) were highly consistent, distinguishable, and independent and could be used as the basis for Malus germplasm taxonomy. The studied 142 taxa were divided into two groups (A, B) and five sub-groups $\left(A_{1}, A_{2}, B_{1}, B_{2}, B_{3}\right)$, with significantly variable floral phenotypic attributes between groups and within sub-groups. Malus natural species were relatively clustered in the same section (series) while homologous cultivars showed evidence of ancestor-inclined distribution characteristics. However, no significant correlation between the evolutionary order of sections (Sect. Docyniopsis $\rightarrow$ Sect. Chloromeles $\rightarrow$ Sect. Sorbomalus $\rightarrow$ Sect. Eumalus) and group/sub-groups $\left(B_{3} \rightarrow B_{2} \rightarrow B_{1} \rightarrow A\right)$.
\end{abstract}

Conclusions: Phenotypic variation of floral organs could better explore the genetic relationship between Malus taxa. The findings improved our cognition of floral phenotypic variation taxonomic significance under the species level.

Keywords: Flowering crabapple, Floral organ phenotype, Numerical taxonomy, Ancestor-inclined distribution, Phenotypic variation, Taxonomic significance

\section{Background}

Flowering crabapples (Malus spp.) are small trees or shrubs in the rose family, characterized by enchanting flowers, colorful small fruits $(\leq 5 \mathrm{~cm})$, and various growth habits. They are also valued for their wide environmental adaptability, facilitating world-wide prominence as gardens and landscape focal points [1-3].

*Correspondence: malus2011@163.com

${ }^{3}$ College of Forestry, Nanjing Forestry University, Nanjing 210037, China

Full list of author information is available at the end of the article
Malus germplasm harbors high level of diversity due to a long period of crossbreeding and natural selection, with steadily growing number of varieties and cultivars compared to their wild ancestors [4-7]. While nearly 1200 Malus taxa were documented in Fiala's "Flowering Crabapple" book, approximately 60 are with known pedigree [8]. It is interesting to note that the majority of the recorded cultivars arose from chance seedlings or selective breeding, thus some of their relationships and genealogy remain unclear [8-12]. 
Flowers, as a unique and highly conserved morphological feature of angiosperms and are often considered as the traditional traits for complex phenotypic identification of different taxonomic groups, as well as evaluating the interplay between evolution and developmental bias [13-15]. Since the information obtained from floral morphological characterizations is consisted of large qualitative and quantitative traits datasets, multivariate analyses are considered to be the most suitable analytical tools for their evaluation [16, 17]. Numerical taxonomy, as one of the multivariate analyses, accelerates the application of systematic taxonomy in plant evolution by quantitatively evaluating the morphological similarity between taxonomic groups [18]. However, the objectivity of the taxonomic results is greatly affected by the selected morphological traits. Recently, in ornamental plant germplasm numerical taxonomy studies, principal component analysis (PCA) is often used to reduce data dimensionality and can be supplemented with one-way analysis of variance (ANOVA) and correlation analysis (R-type cluster analysis: the classification of data objects into similarity groups) $[19,20]$. No scientific system has been formed for trait selection. Moreover, taxonomic units of some studies were solely established above the species level, and the conducted analyses were simply limited to the germplasm identification or clustering group division. This resulted in a failure to correctly locate the role of species, as to conduct in-depth discussion of genetic/evolutionary relationship analysis at or below the species level [21-27].

Based on floral organ phenotypes, we performed numerical taxonomy of 142 Malus taxa to address the following objectives: 1) establishing a scientific system for Malus taxonomic traits selection; 2) revealing the extent of Malus floral organs phenotypic diversity; and 3) clarifying the taxonomic significance (genetic or evolutionary relationships) of Malus floral variation.

\section{Results}

\section{Intraspecific uniformity test and interspecific distinctness} analysis of floral phenotypic traits

Except for the pistil number per flower, the remaining 43 qualitative and quantitative traits had significant intraspecific uniformity $(\overline{M F} \geq 90 \%, \overline{C . v .} \leq 10 \%)$, meeting the requirement for taxa classification (Fig. 1A, B). As for the interspecific distinctness of qualitative traits, it was found that only 15 floral traits (petal surface wrinkle, sepal deflexed, sepal apex shape, flower shape, petal relative position, sepal color, receptacle pubescence, receptacle color, peduncle pubescence, peduncle color, relative position of stigmas and anthers, style color, petal shape, petal outside color, and petal color at the balloon stage) showed a high degree of distinctness among taxa $(M F \leq k 1 / f)$. The remaining 16 qualitative traits, all had no significant interspecific distinctness, and thus should not be further considered in the analyses. It is worth mentioning that although flower type (variable that reflects the number of petal whorls or petals) was less differentiated among the taxa, still it was retained in this analysis for its high recognition value (Fig. 1C). All 13 quantitative traits had a high degree of distinctness (C. $v . \geq 15 \%)$, and could be used as taxonomic trait candidates (Fig. 1D).

\section{Principal component analysis of floral phenotypic traits}

Based on the 28 floral organs phenotypic traits (16 qualitative and 12 quantitative) selected by the above-mentioned intraspecific uniformity test and interspecific distinctness analysis, principal component analysis was then performed. Taking eigenvalue $\lambda>0.85$ as the extraction threshold, a total of 10 principal components mainly consisted of 22 related floral traits were extracted with a cumulative variation contribution of $83.71 \%$, reflecting most of the information of the original floral dataset (Table 1).

As expected, the first principal component (PC1) was the most prominent and accounted for $20 \%$ of variation. Traits integrated by PC1 mainly reflected floral organs color (ordered of their importance: petal color at the balloon stage, peduncle color, sepal color, petal outside color, receptacle color, and style color). PC2 interpreted $18 \%$ of variation and was influenced by flower diameter, petal length, and petal width, which mainly reflected the flower size. PC3 contributed $12 \%$ of the variance mainly through petal length / petal width, petal shape, and petal relative position. PC4 had $9 \%$ of the variance, and partially affected petal number per flower and flower type. PC5 explained 7\% of variation in the pubescence of floral organs (receptacle pubescence and peduncle pubescence). PC6 (5\%) integrated two traits related to the sepal morphology (sepal length / sepal width and sepal apex shape). While the remaining components (PC7: 4\%, PC8: 4\%, PC9: $3 \%$, and PC10: $3 \%$ ), were affected by peduncle length, petal surface wrinkle, relative position of stigmas and anthers, and flower shape, respectively.

\section{Pearson correlation analysis of Malus floral phenotypic traits}

Pearson correlation analysis (taking $r>0.80$ as the critical value) was performed on 22 floral traits selected by the principal component analysis described above (Fig. 2). It was found that most of the traits were independent of each other, and only few were completely or closely related (e.g., flower diameter and petal length $(r=0.98)$, flower diameter and petal width $(r=0.82)$, petal length and petal width $(r=0.81)$, petal number per flower and flower type $(r=0.87)$, petal outside color and petal color 


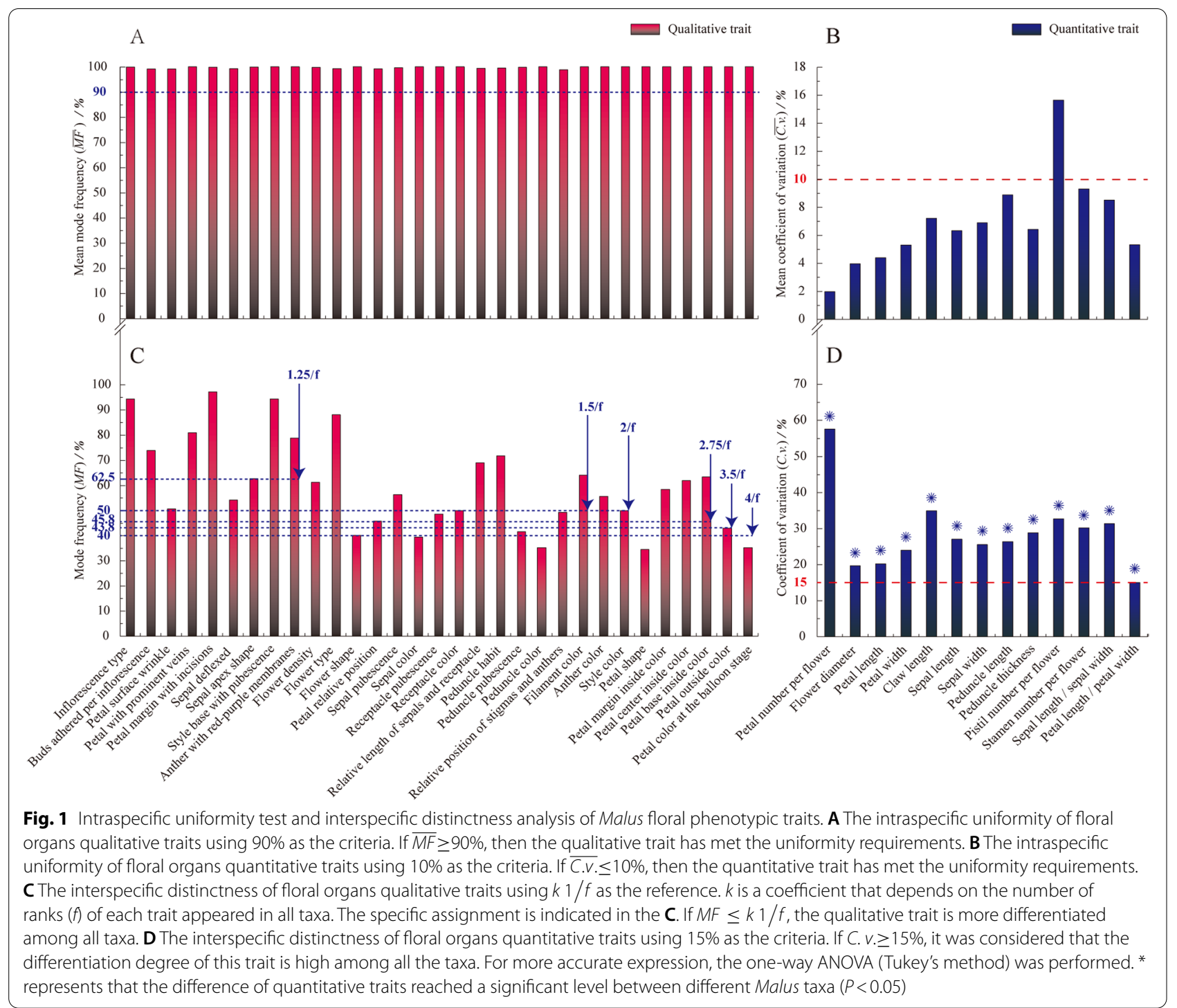

at the balloon stage $(r=0.94)$, peduncle color and sepal color $(r=0.83)$, and receptacle pubescence and peduncle pubescence $(r=0.83))$. For these highly relevant traits, we opted to choose either one of the two traits for taxa classification. It should be pointed out that although lower correlation coefficient existed between petal shape and petal length / petal width $(r=0.61)$, these two traits were logically related in principle and also in this case, either one could be used.

\section{Cluster analysis of Malus taxa based on important phenotypic traits of floral organs}

Finally, 15 important phenotypic traits of floral organs were selected, that are the peduncle color, petal outside color, receptacle color, style color, flower diameter, petal shape, petal relative position, flower type, peduncle pubescence, sepal length / sepal width, sepal apex shape, peduncle length, petal surface wrinkle, relative position of stigmas and anthers, and flower shape. Figure 3 shows the cluster dendrogram of the studied 142 taxa using flexible-beta method based on these 15 floral traits. At Euclidean distances of 21.31 and 11.63, all taxa could be divided into two groups $(A, B)$ and five sub-groups $\left(A_{1}\right.$, $A_{2}, B_{1}, B_{2}$, and $B_{3}$ ), and the characters of floral organs varied significantly between groups and within sub-groups.

Group A: included a total of 64 taxa (45\%) characterized by red flowers and consisted of two sub-groups $\left(A_{1}(50,35 \%)\right.$ and $\left.A_{2}(14,10 \%)\right)$. Taxa in sub-group $A_{1}$ are attractive for their single or semi-double flowers $(4.15 \pm 0.64 \mathrm{~cm}$ in diameter) that are shallow cupshaped or deep cup-shaped. The petals are red- to dark red-purple, as well as the color of receptacles and 
Table 1 Eigenvalue, contribution rate and cumulative contribution rate of each principal component

\begin{tabular}{|c|c|c|c|c|c|c|c|c|c|c|}
\hline $\begin{array}{l}\text { Principal Component } \\
\text { Load coefficient }\end{array}$ & PC 1 & PC 2 & PC 3 & PC 4 & PC 5 & PC 6 & PC 7 & PC 8 & PC 9 & PC 10 \\
\hline \multicolumn{11}{|l|}{ Floral phenotypic traits } \\
\hline Petal color at the balloon stage & 0.93 & 0.11 & 0.11 & -0.05 & -0.08 & -0.01 & 0.03 & -0.09 & -0.01 & 0.02 \\
\hline Peduncle color & 0.90 & -0.01 & -0.05 & 0.08 & 0.04 & 0.12 & -0.03 & -0.04 & 0.05 & 0.09 \\
\hline Sepal color & 0.89 & -0.08 & 0.12 & 0.11 & 0.09 & 0.19 & 0.08 & 0.03 & 0.13 & 0.04 \\
\hline Petal outside color & 0.89 & 0.14 & 0.10 & 0.00 & -0.11 & -0.05 & 0.09 & -0.13 & 0.01 & 0.09 \\
\hline Receptacle color & 0.83 & 0.22 & 0.02 & -0.02 & 0.03 & 0.08 & -0.14 & 0.06 & 0.16 & 0.06 \\
\hline Style color & 0.75 & -0.13 & -0.09 & 0.22 & 0.07 & -0.14 & 0.05 & 0.01 & -0.23 & 0.08 \\
\hline Flower diameter & 0.11 & 0.95 & 0.02 & 0.12 & -0.11 & -0.06 & 0.04 & 0.02 & -0.08 & 0.10 \\
\hline Petal length & 0.11 & 0.94 & 0.02 & 0.07 & -0.07 & -0.08 & 0.07 & 0.05 & 0.02 & 0.11 \\
\hline Petal width & 0.04 & 0.81 & -0.48 & 0.06 & -0.11 & 0.05 & 0.11 & 0.06 & -0.01 & 0.08 \\
\hline Sepal length & -0.11 & 0.68 & -0.20 & -0.33 & -0.09 & -0.43 & -0.06 & 0.05 & -0.04 & -0.20 \\
\hline Peduncle thickness & -0.06 & 0.59 & -0.17 & 0.06 & -0.50 & 0.18 & -0.10 & 0.26 & 0.02 & -0.21 \\
\hline Claw length & 0.11 & 0.58 & 0.26 & 0.18 & -0.26 & -0.05 & -0.11 & -0.34 & -0.31 & 0.21 \\
\hline Sepal width & -0.02 & 0.56 & -0.38 & -0.08 & -0.26 & 0.47 & 0.03 & 0.23 & 0.05 & -0.25 \\
\hline Petal length / Petal width & 0.09 & -0.08 & 0.86 & -0.02 & 0.10 & -0.22 & -0.11 & 0.01 & 0.08 & -0.01 \\
\hline Petal shape & 0.12 & -0.06 & 0.79 & 0.15 & 0.04 & -0.03 & 0.13 & 0.18 & -0.09 & 0.07 \\
\hline Petal relative position & 0.05 & 0.12 & -0.74 & 0.30 & -0.04 & 0.10 & 0.02 & 0.24 & 0.13 & 0.06 \\
\hline Petal number per flower & 0.11 & 0.08 & -0.05 & 0.94 & 0.00 & -0.03 & 0.15 & 0.06 & -0.07 & -0.06 \\
\hline Flower type & 0.10 & 0.07 & -0.04 & 0.93 & 0.04 & 0.15 & 0.04 & 0.08 & 0.01 & 0.09 \\
\hline Receptacle pubescence & -0.03 & -0.20 & 0.06 & 0.05 & 0.92 & 0.02 & 0.08 & 0.07 & 0.03 & -0.04 \\
\hline Peduncle pubescence & 0.03 & -0.14 & 0.08 & -0.01 & 0.91 & 0.04 & 0.04 & -0.02 & 0.07 & 0.12 \\
\hline Sepal length / Sepal width & -0.04 & 0.11 & 0.16 & -0.07 & 0.13 & -0.86 & -0.02 & -0.16 & -0.17 & -0.06 \\
\hline Sepal apex shape & 0.15 & -0.04 & -0.20 & 0.08 & 0.23 & 0.74 & 0.00 & -0.16 & -0.11 & -0.05 \\
\hline Peduncle length & 0.04 & 0.08 & -0.05 & 0.12 & 0.15 & -0.04 & 0.90 & 0.03 & 0.04 & 0.16 \\
\hline Pistil number per flower & -0.02 & 0.10 & 0.25 & 0.44 & -0.13 & 0.35 & 0.53 & 0.11 & 0.05 & -0.33 \\
\hline Petal surface wrinkle & -0.10 & 0.12 & 0.03 & 0.14 & 0.01 & 0.02 & 0.06 & 0.85 & -0.10 & 0.07 \\
\hline Relative position of stigmas and anthers & 0.16 & -0.14 & -0.11 & 0.01 & 0.11 & 0.09 & 0.07 & -0.08 & 0.83 & -0.06 \\
\hline Sepal deflexed & -0.44 & 0.17 & 0.10 & -0.28 & -0.13 & -0.14 & -0.36 & -0.11 & 0.45 & 0.10 \\
\hline Flower shape & 0.26 & 0.12 & 0.01 & 0.02 & 0.10 & 0.01 & 0.11 & 0.08 & -0.04 & 0.85 \\
\hline Eigenvalue & 5.50 & 5.11 & 3.25 & 2.50 & 1.86 & 1.35 & 1.04 & 0.99 & 0.97 & 0.87 \\
\hline Contribution rate / \% & 19.66 & 18.26 & 11.60 & 8.93 & 6.64 & 4.81 & 3.72 & 3.53 & 3.45 & 3.11 \\
\hline Cumulative contribution rate / \% & 19.66 & 37.92 & 49.52 & 58.45 & 65.09 & 69.90 & 73.62 & 77.15 & 80.60 & 83.71 \\
\hline
\end{tabular}

The cumulative contribution rate means the representativeness of extracted factors for all variables. Generally, $80 \%$ is regarded as the critical value. And the larger the value, the stronger the representativeness. The meaning of each principal component is determined by the absolute value of load coefficient. Variables with an absolute value greater than 0.7 can be considered as representative ones of the principal component

peduncles. The relative position of petals is touching or overlapping. Sepal shape of flowers in this sub-group is lanceolate, and their apexes are acuminate in majority. Peduncles are medium in length $(2.75 \pm 0.75 \mathrm{~cm})$, mostly with no or sparse pubescence. Relative to anthers, stigmas are above or the same height. In subgroup $\mathrm{A}_{2}$, the flowers are large $(4.87 \pm 0.75 \mathrm{~cm}$ in diameter), charming with double (15-27 petals), light pink to deep pink, wrinkled petals. The flower shape is flat or deep cup-shaped, and the petals is elliptic. Relative position of petals is overlapping. The sepals are triangular, and their apexes are mostly acute. Peduncles are long $(3.16 \pm 0.52 \mathrm{~cm})$. In this sub-group, the relative position of stigmas and anthers varied.

Group B: included 78 taxa (55\%) and are distinguished by their single, pinkish white or white flowers, gradually changing from pink to rose-red or pure white buds. It contained three sub-groups $\left(B_{1}(21\right.$, $15 \%), B_{2}(36,25 \%)$ and $B_{3}(21,15 \%)$. The degree of petal color rhythm (petal color changes during the different flowering stages) of the three sub-groups was $B_{1}>B_{3}>B_{2}$. In sub-group $B_{1}$, taxa are unique for their small $(3.44 \pm 0.88 \mathrm{~cm})$ flowers that are flat or shallow cup-shaped. Petal shapes are mostly round to ovate, 


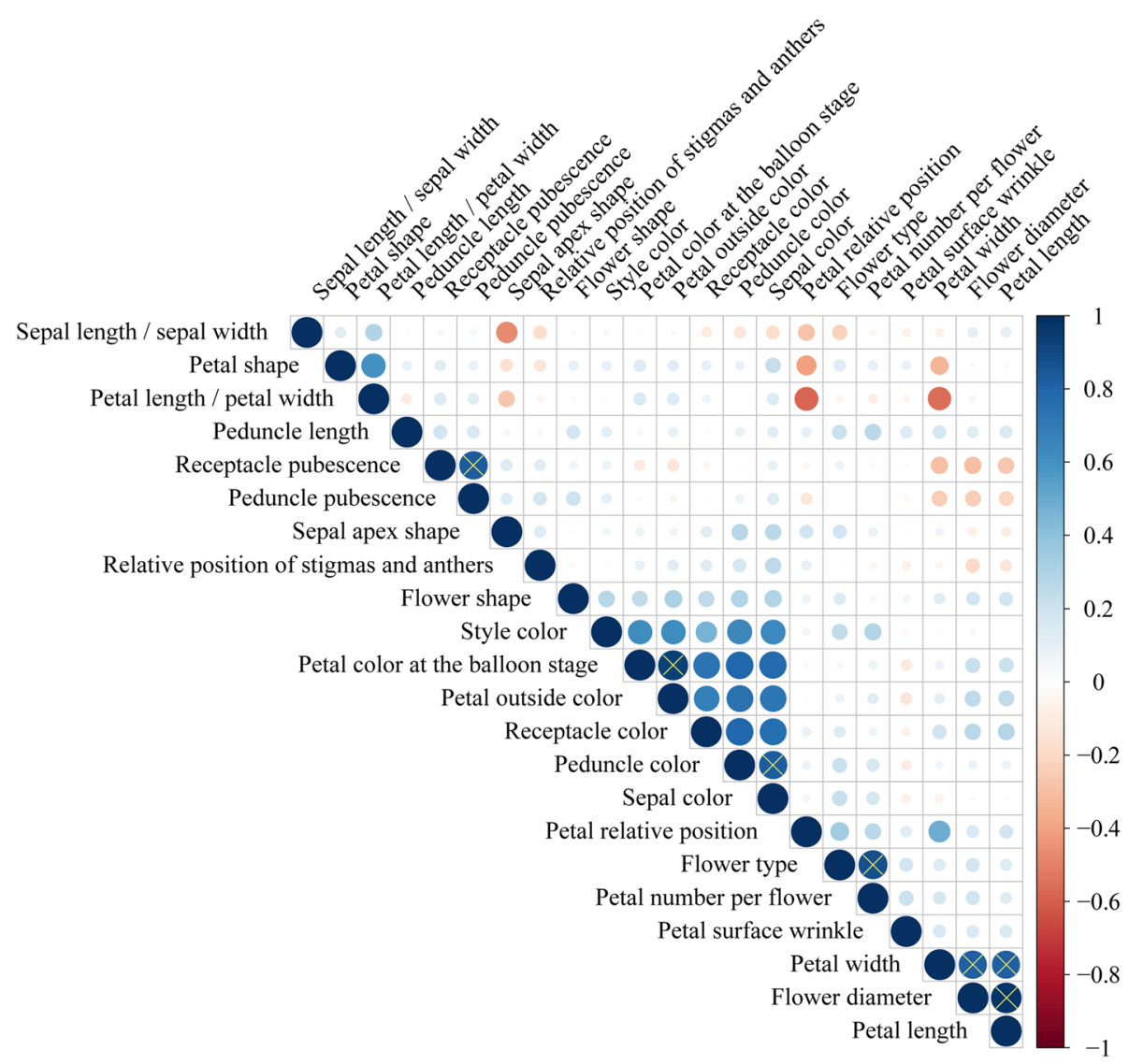

Fig. 2 Pearson correlation analysis of Malus floral phenotypic traits. The circle marked with ' $x$ ' represents that the correlation index between phenotypic traits of floral organs is over $0.80(r>0.80)$. For these highly relevant traits, we opted to choose either one of the two traits when classifying the taxa

and the petals are overlapping with each other. Flowers in this sub-group have red-purple receptacles, triangular sepals, and acute sepal apexes. The peduncles are medium in length $(2.72 \pm 0.49 \mathrm{~cm})$, covered with sparse or dense pubescence in its red-purple epidermis. Stigmas are almost of the same height as anthers. In sub-group $B_{2}$, flowers are differed for their medium diameter $(4.21 \pm 0.73 \mathrm{~cm})$, with flat or shallow cupped, rarely deep cup-shaped colloras. The petal shapes range from ovate to elliptic and their surface is usually wrinkled. Relative position of petals is contacting or overlapping. Peduncles are medium in length $(2.69 \pm 0.87 \mathrm{~cm})$, covered with no pubescence on their epidermis. Sepal shapes are long lanceolate, and their apexes are acuminate. Receptacles and peduncles color is majorly green or reddish green. As for the sub-group $\mathrm{B}_{3}$, flowers are also small in diameter $(3.41 \pm 0.51 \mathrm{~cm})$, with flat or shallow cupped corollas. The petals are elliptic or narrow elliptic, and their relative position is free or touching. Receptacles and peduncles color is green or reddish green. Thinly or densely hairy are observed in the surface of peduncles. Compared with the other two sub-groups, peduncle length in subgroup $\mathrm{B}_{3}$ is relatively shorter $(2.43 \pm 0.53 \mathrm{~cm})$. The sepals are lanceolate with acuminate apexs. In this subgroup, stigmas are mostly of the same or higher than the anthers height.

(See figure on next page.)

Fig. 3 Clustering dendrogram of Malus taxa based on important phenotypic traits of floral organs. At Euclidean distances of 21.31 and 11.63, all the 142 taxa were divided into two groups (A, B) and five sub-groups $\left(A_{1}, A_{2}, B_{1}, B_{2}\right.$, and $\left.B_{3}\right)$, and the characters of floral organs varied significantly between groups and within sub-groups. Taxa belonged to the same sub-groups were labeled with the same color, and the floral organs dynamic map of typical Malus taxa for each sub-group was presented in the right rectangular box with corresponding color 


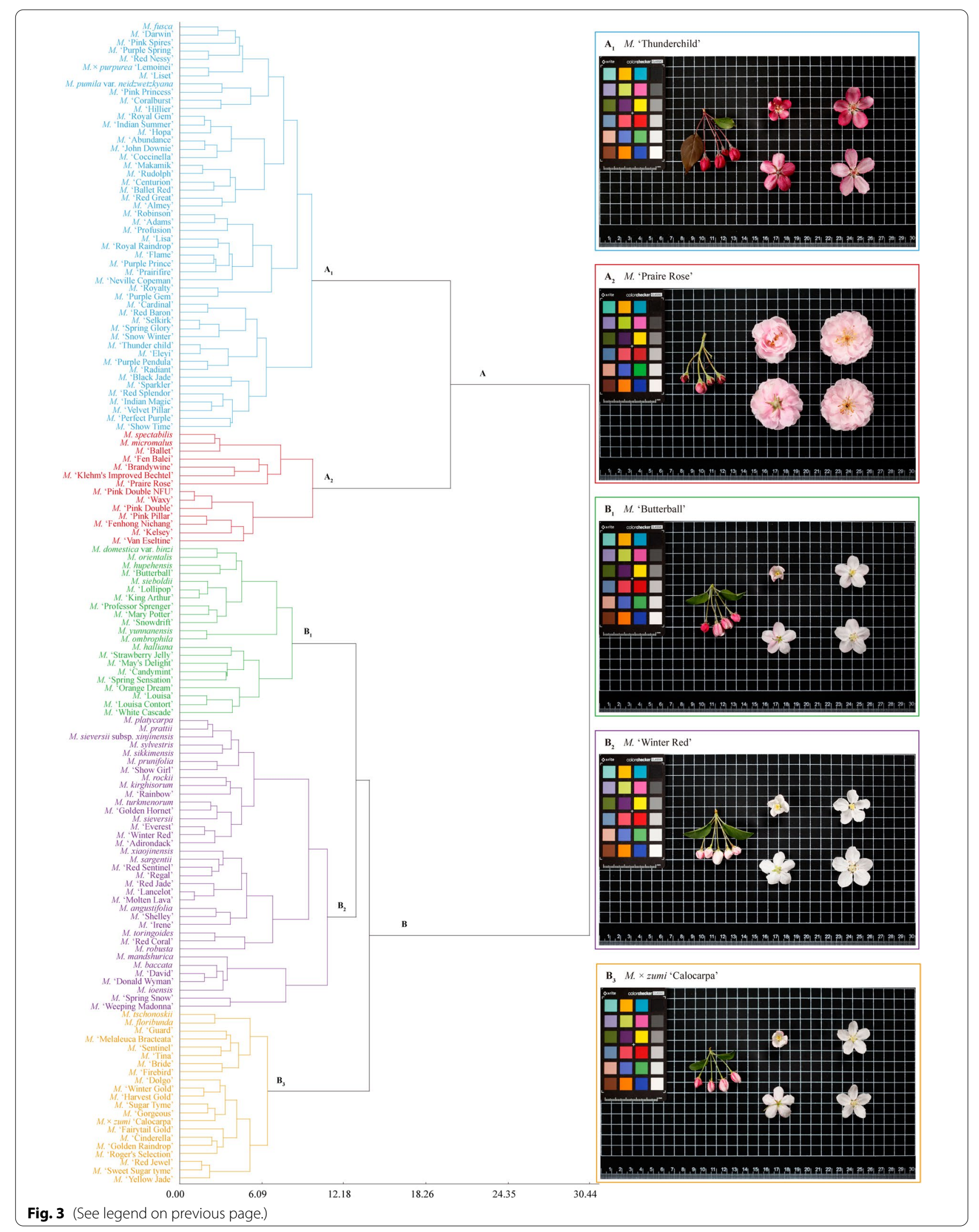




\section{Ancestor-inclined distribution characteristic analysis of Malus taxa}

In this study, ancestor-inclined distribution characteristics of Malus taxa were analyzed from two aspects: species and cultivars. In accordance with the Malus species taxonomy system proposed by Rehder [28], Yu et al. [29], and Li et al. [30], the 31 species involved in our study belonged to seven sections (series): I, Sect. Docyniopsis (one species); II, Sect. Chloromeles (three species); III, Ser. Yunnanenses of Sect. Sorbomalus (three species); IV, Ser. Kansuenses of Sect. Sorbomalus (three species); V, Ser. Sieboldianae of Sect. Sorbomalus (three species); VI, Ser. Baccatae of Sect. Eumalus (six species); and VII, Ser. Pumilae of Sect. Eumalus (12 species) (Fig. 4). The distribution of Malus species belonged to the same section (series) was relatively concentrated. The ancestor-inclined distribution probability reached up to $87 \%$ in the two groups and $61 \%$ in five sub-groups. From the literature, 33 out of the 111 tested Malus cultivars could be completely or partially traced back to their parental taxa (11 species with the floral organ phenotypic data involved in this study) [8-10, 12]. Statistical analysis indicated that the studied 33 cultivars also showed obvious ancestor-inclined distribution characteristics in two groups $(A, B)$ and five sub-groups $\left(A_{1}, A_{2}\right.$, $\mathrm{B}_{1}, \mathrm{~B}_{2}, \mathrm{~B}_{3}$ ), with inclined probability reaching up to 73 and $64 \%$, respectively (Table 2 ).

Based on the above distribution characteristics of Malus species in the two groups (A, B) and five subgroups $\left(A_{1}, A_{2}, B_{1}, B_{2}, B_{3}\right)$, it was inferred that the evolutionary order of the four groups/sub-groups $\left(A, B_{1}\right.$, $B_{2}$, and $B_{3}$ ) in this study might be: $B_{3} \rightarrow B_{2} \rightarrow B_{1} \rightarrow A$. According to the order from original to evolved, these four groups/sub-groups and the four sections of Malus species in classic taxonomy system were assigned by values: $\mathrm{B}_{3}(1) \rightarrow \mathrm{B}_{2}(2) \rightarrow \mathrm{B}_{1}(3) \rightarrow \mathrm{A}$ (4), Sect. Docyniopsis $(1) \rightarrow$ Sect. Chloromeles $(2) \rightarrow$ Sect. Sorbomalus (3) $\rightarrow$ Sect. Eumalus (4). It was also found that there was no significant correlation between these two sets of evolutionary data $\left(R^{2}=0.068, P=0.156\right)$.

\section{Discussion}

\section{Establishment of a screening system for Malus floral} taxonomic traits

Typical angiosperm flowers are composed of sterile sepals and petals and fertile stamens and carpels [31-33].
The significant differences in the number, type, size, shape, color, arrangement, and smell of each part determine its multi-dimensional and complex characteristics $[14,34,35]$. Uni-dimensional variables are usually difficult to describe in its entirety, while the specificity of different groups could be easily masked when several variables were simultaneously considered. Currently, dimensionality reduction of traits is often performed by principal component analysis (PCA) or correlation analysis (R-type cluster analysis), or by artificial screening based on intuitive experience [2, 36, 37]. No systematic and scientific system has been formed for trait screening. In this study, for meeting the requirements of Malus taxonomy and aesthetic, a theoretical and technical system (intraspecific uniformity test $\rightarrow$ interspecific distinctness analysis and one-way ANOVA $\rightarrow$ principal component analysis $\rightarrow$ Pearson correlation analysis) was established in accordance with the order of uniformity $\rightarrow$ distinctness $\rightarrow$ independence. Twelve qualitative (petal outside color, peduncle color, receptacle color, style color, petal shape, petal relative position, flower type, peduncle pubescence, sepal apex shape, flower shape, petal surface wrinkle, and relative position of the stigmas and anthers) and three quantitative traits (flower diameter, peduncle length, and sepal length/sepal width) were finally extracted, and these traits could reflect most of the information present in the original Malus floral dataset. This theoretical and technical trait screening system also has important reference for the extraction of phenotypic characteristics in taxonomy of other ornamental plant resources.

\section{Taxonomic significance of phenotypic variation of Malus floral organs}

Floral variation is a positive response of plants to the selection pressure [38-41]. Studies on floral variation not only contributed to our understanding of species evolution [42-45], but also revealed the genetic rules and variation degrees of populations / groups [46-50], which in turn provided a theoretical basis for the protection of species. In this study, through the cluster analysis of the 142 Malus taxa based on their floral organs phenotypic traits, we found that the distribution of Malus species belonged to the same section (series) was relatively concentrated, with ancestor-inclined distribution

(See figure on next page.)

Fig. 4 Ancestor-inclined distribution characteristics and genetic relationship analysis of Malus taxa. According to the Malus species taxonomy system proposed by Rehder (1940) [28], Yu et al. (1956) [29], and Li et al. (2001) [30], the 31 species involved in this study belonged to seven sections (series): I, Sect. Docyniopsis (one species); II, Sect. Chloromeles (three species); III, Ser. Yunnanenses of Sect. Sorbomalus (three species); IV, Ser. Kansuenses of Sect. Sorbomalus (three species); V, Ser. Sieboldianae of Sect. Sorbomalus (three species); VI, Ser. Baccatae of Sect. Eumalus (six species); and VII, Ser. Pumilae of Sect. Eumalus (12 species). The order from I to VII corresponded with the sequence of sect/series evolution. Species in the same section (seris) were labeled with the same color. Then the ancestor-inclined distribution characteristics of Malus taxa were analyzed from two aspects: species and cultivars, based on the clustering dendrogram of all 142 Malus taxa 


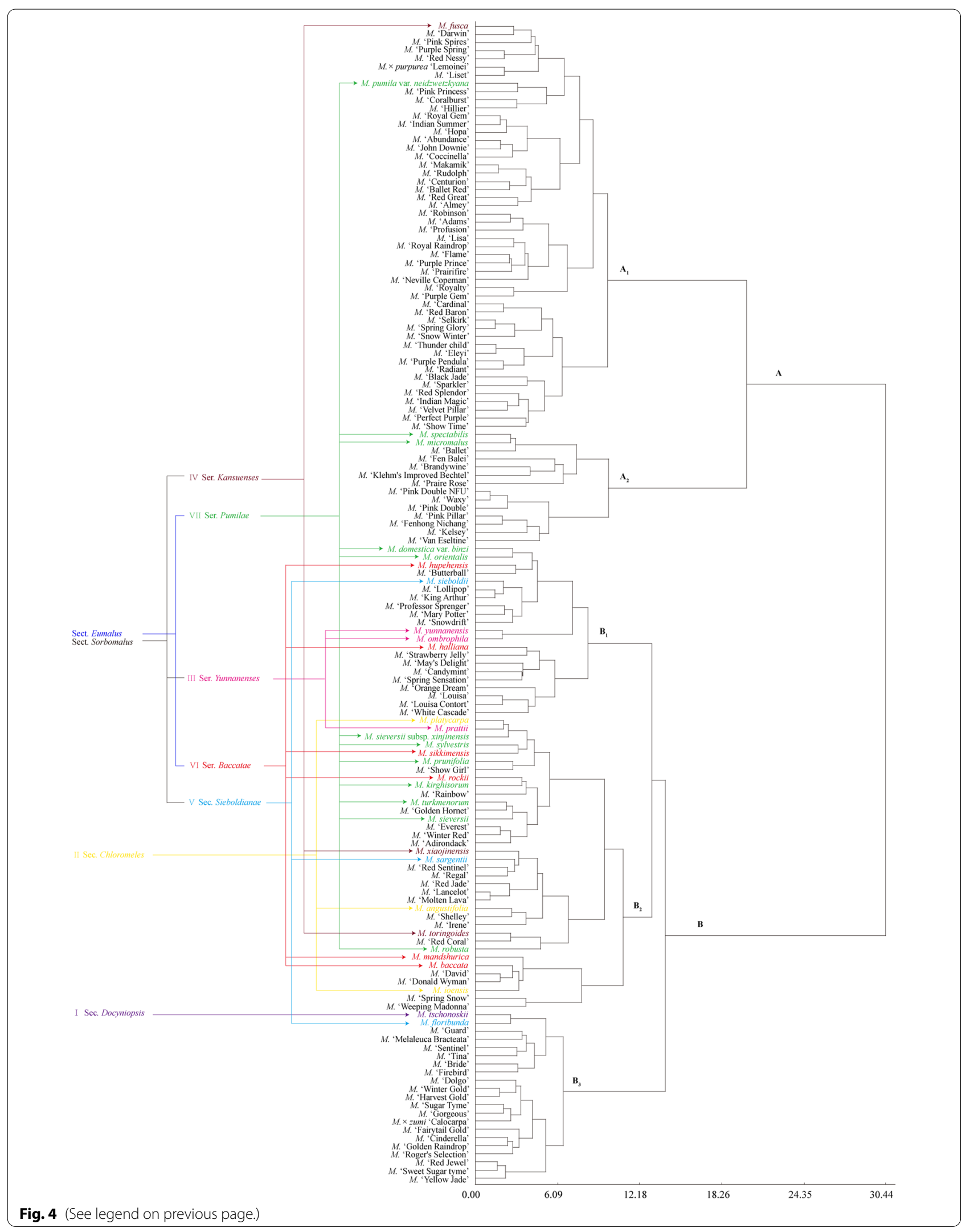


Table 2 Parents traceability and identification of ancestor-inclined distribution characteristics of Malus cultivars

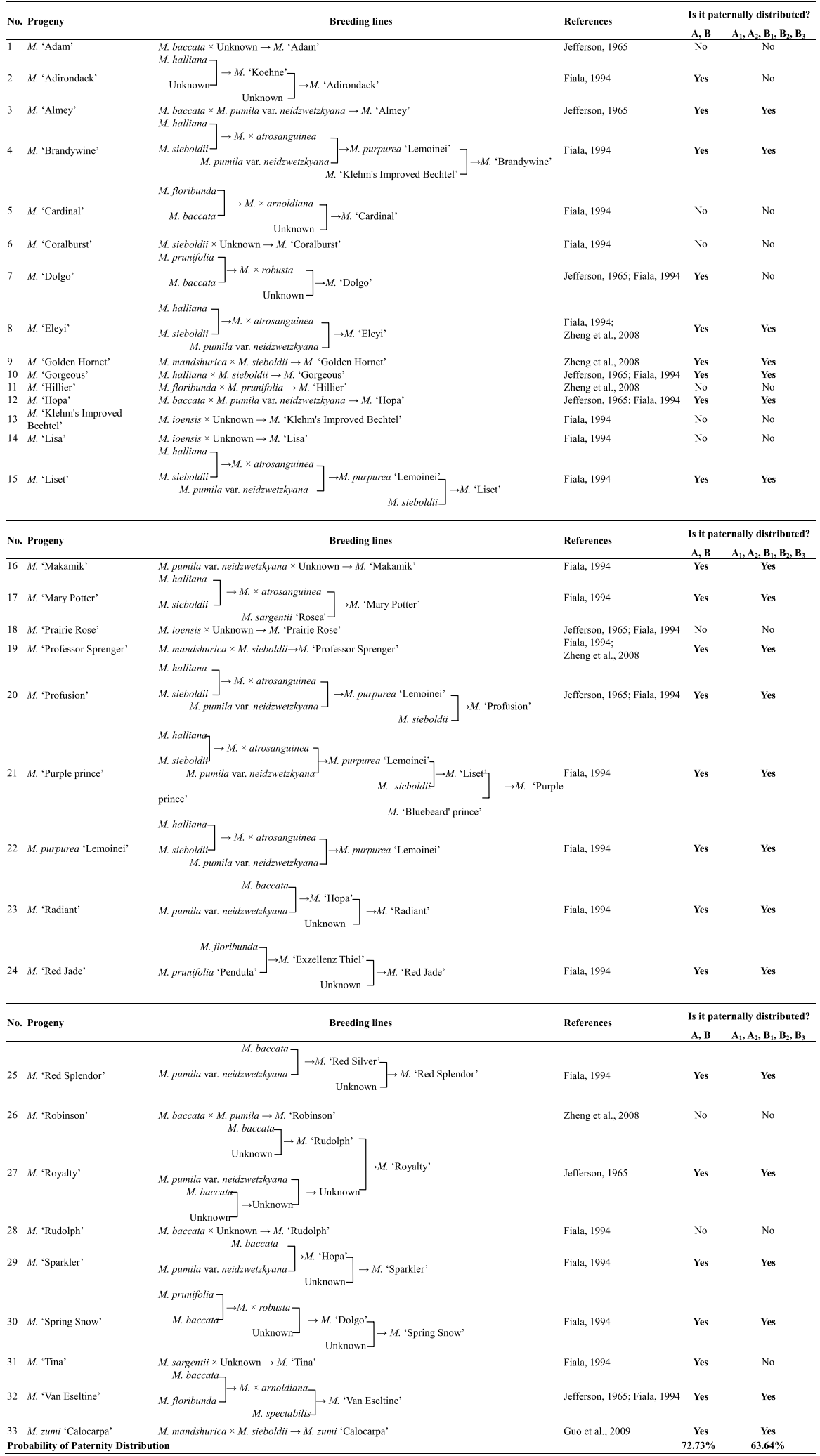


probability reaching up to $87 \%$ in two groups $(\mathrm{A}, \mathrm{B})$ and $61 \%$ in five sub-groups $\left(A_{1}, A_{2}, B_{1}, B_{2}, B_{3}\right)$. Among the 33 cultivars that could be traced to all or part of their parents, evident ancestor-inclined distribution characteristics were also observed in the above mentioned groups / sub-groups (the ancestor-inclined distribution probability reaching up to 73 and 64\%, respectively). Our results agreed with the classical Malus taxonomy system established by Rehder [28], indicating that the phenotypic variation of floral organs could be well applied to the genetic relationship exploration between Malus taxa. However, by comparing the evolutionary order of Malus sections (Sect. Docyniopsis $\rightarrow$ Sect. Chloromeles $\rightarrow$ Sect. Sorbomalus $\rightarrow$ Sect. Eumalus) proposed by Langenfel' $D$ [51] based on classic phenotypic traits with that of Malus groups / sub-groups $\left(\mathrm{B}_{3} \rightarrow \mathrm{B}_{2} \rightarrow \mathrm{B}_{1} \rightarrow \mathrm{A}\right)$ inferred from the cluster dendrogram of the 142 Malus taxa, it was found that there was no significant correlation between them $\left(R^{2}=0.068, P=0.156\right)$. This indicated that floral variation is unable to reveal the evolutionary relationships of Malus species. In fact, the variation or change in different floral organs usually occurs at different taxonomic levels (family, genus, species, ranks below species) [52]. Size, color, smell, and the taste of floral organs are often quite different in species or lower levels [45, 53-55]. Jin [56] concluded that in the taxonomy of subgenus Tsutsusz (Rhododendron), the tree habit, shape and the size of corollas, could be used to distinguish grades above the species level. The pubescence type of young twigs, number of stamens, size of calyx lobes, pubescence condition of filament or corolla, etc. could be applied in the delimitation of species (taxa below species). In some cases, the pubescence condition of style could be limitedly adopted, while some important traits such as whether stamens are longer than pistils and whether stamens are equal in length should be better avoided. For exploring the evolutionary relationship of Malus species based on the phenotypes of floral organs, the screening of taxonomic traits varied at the species level is therefore playing the key role.

\section{Conclusions}

This study innovatively established a scientific system (intraspecific uniformity test $\rightarrow$ interspecific distinctness analysis and one-way ANOVA $\rightarrow$ principal component analysis $\rightarrow$ Pearson correlation analysis) for Malus taxonomic traits screening in accordance with the order of uniformity $\rightarrow$ distinctness $\rightarrow$ independence. This scientific system also has important reference for the extraction of phenotypic characteristics in taxonomy of other ornamental plant resources. Based on numerical taxonomy, phenotypic variation of Malus floral organs was then clearly clarified, as well as its taxonomic significance: Phenotypic variation of floral organs could better explore the genetic relationship between Malus taxa. These findings improved our cognition of floral phenotypic variation taxonomic significance under the species level.

\section{Methods \\ Plant materials}

A total of 142 Malus taxa (including 31 species and 111 cultivars) were collected from the National Repository of Malus spp. Germplasm (Yangzhou City, Jiangsu Province, China) (Table 3). All trees were 7 to 10 years old and entered the full blooming phase. Each cultivar was represented by 30 individuals planted with $3 \mathrm{~m}$ between rows and $2 \mathrm{~m}$ within rows. According to the requirements of randomized block experiment design, 10 plants were taken as one block, and three blocks were set for each taxon.

\section{Trait measurement, description, and coding}

For each cultivar, 10 plants were randomly selected and three consistent, typical and standard full-bloom flowers for each plant were collected, yielding 30 samples in total. All flowers were gathered from the middle of the tree and the branch exposed to the sun. Then, they were placed in a cooler and taken to the laboratory for immediate measurement.

Phenotypic traits evaluation was carried out as recommended by the guidelines for Malus distinctness, uniformity and stability test [57] and additional traits were specifically selected for their identification value. All together 44 phenotypic traits of Malus floral organs were investigated in this study, including 31 qualitative traits (dimorphic traits and polymorphic traits that can only be observed and present discontinuous variation) and 13 quantitative traits (traits that can be differentiated by quantity and present continuous variation) [58] (Table 4).

For four consecutive years (2017 to 2020: end of March to mid-April or late April), the 44 traits were repeatedly assessed for correction. Qualitative traits were directly observed in the field, and the final values of quantitative traits were calculated as the mean value of 30 replicates. Hierarchical number coding system was applied for the qualitative traits following the order from ancestral to evolutionary as far as possible. Consecutively arranged non-negative integers $0,1,2,3, \ldots$, were taken for expression. The dimorphic traits with an evolutionary relationship that was difficult to determine were generally coded as 1 (Yes) and 0 (No) [59, 60]. No coding was applied for the quantitative traits and the mean values of the 30 replicates were directly used for further analysis (Table 4). 
Table 3 List of the 142 taxa collected from the national repository of Malus germplasm

\begin{tabular}{|c|c|c|c|c|}
\hline No. Species & No. Cultivars & No. Cultivars & No. Cultivars & No. Cultivars \\
\hline 1 Malus angustifolia & 32M. 'Abundance' & 63 M. 'Harvest Gold' & 94 M. 'Professor Sprenger' & 125 M.'Sparkler' \\
\hline 2M. baccata & 33 M.'Adam' & 64M. 'Hillier' & 95 M.'Profusion' & 126 M. 'Spring Glory' \\
\hline 3 M. domestica var.binzi & 34M. 'Adirondack' & 65 M. 'Hopa' & 96 M. 'Purple Gem' & 127 M. 'Spring Sensation' \\
\hline 4M. floribunda & 35 M. 'Almey' & 66 M. 'Indian Magic' & 97 M. 'Purple Pendula' & 128M.'Spring Snow' \\
\hline 5 M. fusca & 36M.'Ballet' & 67 M. 'Indian Summer' & 98M.'Purple Prince' & 129M. 'Strawberry Jelly' \\
\hline 6M. halliana & 37 M. 'Ballet Red' & 68M.'Irene' & 99M. 'Purple Spring' & 130 M.'Sugar Tyme' \\
\hline 7M. hupehensis & 38M. 'Black Jade' & 69 M. 'John Downie' & 100 M. × purpurea 'Lemoinei' & 131 M.'Sweet Sugartyme' \\
\hline $8 \mathrm{M}$. ioensis & 39 M.'Brandywine' & 70 M. 'Kelsey' & 101 M.'Radiant' & 132M.'Thunderchild' \\
\hline 9M. kirghisorum & 40 M. 'Bride' & 71 M. 'King Arthur' & 102 M. 'Rainbow' & 133 M.'Tina' \\
\hline 10 M. mandshurica & 41 M. 'Butterball' & 72 M. 'Klehm's Improved Bechtel' & 103 M.'Red Baron' & 134M. 'Van Eseltine' \\
\hline 11 M. micromalus & $42 \mathrm{M}$. 'Candymint' & 73 M. 'Lancelot' & 104 M.'Red Coral' & 135 M. 'Velvet Pillar' \\
\hline 12M. ombrophila & 43M. 'Cardinal' & 74M. 'Lisa' & 105 M.'Red Great' & 136 M.'Waxy' \\
\hline $13 \mathrm{M}$. orientalis & 44M. 'Centurion' & 75 M. 'Liset' & 106 M.'Red Jade' & 137 M.'Weeping Madonna \\
\hline 14M.platycarpa & 45 M. 'Cinderella' & 76M. 'Lollipop' & 107 M. 'Red Jewel' & 138 M. 'White Cascade' \\
\hline $15 \mathrm{M}$.prattii & 46 M. 'Coccinella' & 77 M. 'Louisa' & 108M.'Red Nessy' & 139M. 'Winter Gold' \\
\hline 16 M.prunifolia & $47 \mathrm{M}$. 'Coralburst' $^{\prime}$ & 78M. 'Louisa Contort' & 109 M.'Red Sentinel' & 140 M. 'Winter Red' \\
\hline 17M. pumila var. neidzwetzkyana & 48M. 'Darwin' & 79M. 'Makamik' & 110 M. 'Red Splendor' & 141 M. 'Yellow Jade' \\
\hline $18 \mathrm{M}$. robusta & 49M. 'David' & 80 M. 'Mary Potter' & 111 M. 'Regal' & 142 M. $\times$ zumi'Calocarpa' \\
\hline 19M. rockii & 50 M. 'Dolgo' & 81 M. 'May's Delight' & 112M.'Robinson' & \\
\hline 20M. sargentii & 51 M. 'Donald Wyman' & 82 M. 'Melaleuca Bracteata' & 113 M. 'Roger's Selection' & \\
\hline 21 M.sieboldii & 52 M.'Eleyi' & 83 M. 'Molten Lava' & 114M.'Royal Gem' & \\
\hline $22 \mathrm{M}$. sieversii & 53 M. 'Everest' & 84M. 'Neville Copeman' & 115 M.'Royal Raindrop' & \\
\hline 23 M. sieversii subsp. xinjinensis & 54 M. 'Fairytail Gold' & 85 M. 'Orange Dream' & 116 M.'Royalty' & \\
\hline $24 M$. sikkimensis & 55M. 'Fen Balei' & 86 M. 'Perfect Purple' & 117 M.'Rudolph' & \\
\hline 25 M. spectabilis & 56 M. 'Fenhong Nichang' & 87 M.'Pink Double' & 118M.'Selkirk' & \\
\hline 26M. sylvestris & 57 M. 'Firebird' & 88M. 'Pink Double NFU' & 119M.'Sentinel' & \\
\hline 27 M. toringoides & $58 \mathrm{M} .{ }^{\prime}$ Flame' $^{\prime}$ & 89 M. 'Pink Pillar' & 120 M.'Shelley' & \\
\hline 28M.tschonoskii & 59 M. 'Golden Hornet' & 90 M. 'Pink Princess' & 121 M. 'Show Girl' & \\
\hline 29M. turkmenorum & 60 M. 'Golden Raindrop' & 91 M. 'Pink Spires' & 122 M. 'Show Time' & \\
\hline 30M.xiaojinensis & $61 \mathrm{M}$. 'Gorgeous' & 92 M. 'Praire Rose' & 123M.'Snowdrift' & \\
\hline 31 M. yunnanensis & 62 M. 'Guard' & 93M. 'Prairifire' & 124 M. 'Snow winter' & \\
\hline
\end{tabular}

The taxa numbered from 1 to 31 are Malus species, and from 32 to 142 are Malus cultivars

\section{Screening of taxonomic traits}

To obtain the traits that are highly consistent, distinguishable, and independent, a scientific system for Malus taxonomic traits screening was established (Fig. 5).

\section{Intraspecific uniformity test}

The intraspecific uniformity test for qualitative traits is expressed by the mean mode frequency $(\overline{M F})$, and for quantitative traits is expressed by the mean coefficient of variation $(\overline{C . v .})$. If $\overline{M F} \geq 90 \%$ or $\overline{C . v .} \leq 10 \%$, then the qualitative (quantitative) trait has met the uniformity requirements.

$$
\overline{M F}=\frac{1}{n} \sum_{i=1}^{n}\left(\operatorname{Count}\left(M_{0}\right) / m\right) \times 100 \%
$$

$$
\overline{C . v .}=\frac{1}{n} \sum_{i=1}^{n}\left(S_{i} / \bar{X}_{i}\right) \times 100 \%=\frac{1}{n} \sum_{i=1}^{n} \frac{\sqrt{\left.\frac{1}{m-1} \sum_{j=1}^{m}\left(X_{i j}-\overline{X_{i}}\right)^{2}\right)}}{\left(X_{i 1}+X_{i 2}+\ldots \cdots+X_{i m}\right) / m} \times 100 \%
$$

where $n$ denotes the number of taxa; $m$ denotes the number of repetitions; $M_{0}, S_{i}$ and $\overline{X_{i}}$ denotes the rank with highest frequency of occurrence, standard deviation of the observed values, and the mean observed values of each trait in each taxa's $m$ repetitions, respectively. 
Table 4 Description and coding of the assessed Malus floral phenotypic traits

\begin{tabular}{|c|c|c|}
\hline No. & Phenotypic trait & Trait description (grade) and coding \\
\hline 1 & Flower density & Dense (0); Medium (1); Sparse (2) \\
\hline 2 & Inflorescence type & Corymbiform (0); Umbellate (1) \\
\hline 3 & Buds adhered per inflorescence & No $(0) ; Y e s(1)$ \\
\hline 4 & Flower type & Single (0); Semi-double (1); Double (2) \\
\hline 5 & Flower shape & Flat (0); Shallow cup (1); Deep cup (2) \\
\hline 6 & Flower diameter & Assessed in $\mathrm{mm}$ \\
\hline 7 & Petal color at the balloon stage & $\begin{array}{l}\text { Yellow green (0); White (1); Pinkish White (2); Light pink (3); Deep pink (4); Rose (5); Light red-purple (6); } \\
\text { Deep red-purple (7); Deep red (8); Dark red-purple (9) }\end{array}$ \\
\hline 8 & Petal outside color & $\begin{array}{l}\text { White (0); Pinkish white (1); Light pink (2); Deep pink (3); Rose (4); Light red-purple (5); Deep red-purple } \\
\text { (6); Dark red-purple (7) }\end{array}$ \\
\hline 9 & Petal margin inside color & White (0); Pinkish white (1); Light pink (2); Light red-purple (3); Deep red-purple (4); Dark red-purple (5) \\
\hline 10 & Petal center inside color & White (0); Pinkish white (1); Light pink (2); Light red-purple (3); Deep red-purple (4); Dark red-purple (5) \\
\hline 11 & Petal base inside color & White (0); Pinkish white (1); Light pink (2); Light red-purple (3); Deep red-purple (4); Dark red-purple (5) \\
\hline 12 & Petal relative position & Separated (0); Touching (1); Overlapping (2) \\
\hline 13 & Petal number per flower & Counted \\
\hline 14 & Petal shape & Circular (0); Oval (1); Ovate (2); Obovate (3); Elliptic (4); Narrow elliptic (5) \\
\hline 15 & Petal surface wrinkle & No $(0) ; Y e s(1)$ \\
\hline 16 & Petal with prominent veins & No (0); Yes (1) \\
\hline 17 & Petal margin with incisions & No (0); Yes (1) \\
\hline 18 & Petal length & Assessed in $\mathrm{mm}$ \\
\hline 19 & Petal width & Assessed in $\mathrm{mm}$ \\
\hline 20 & Petal length / Petal width & Calculated \\
\hline 21 & Claw length & Assessed in mm \\
\hline 22 & Sepal color & Green (0); Reddish green (1); Red-purple (2) \\
\hline 23 & Sepal apex shape & Acuminate (0); Acute (1) \\
\hline 24 & Sepal deflexed & No (0); Yes (1) \\
\hline 25 & Sepal pubescence & Dense (0); Sparse (1); None (2) \\
\hline 26 & Sepal length & Assessed in $\mathrm{mm}$ \\
\hline 27 & Sepal width & Assessed in $\mathrm{mm}$ \\
\hline 28 & Sepal length / Sepal width & Calculated \\
\hline 29 & Receptacle color & Green (0); Reddish green (1); Red-purple (2) \\
\hline 30 & Receptacle pubescence & Dense (0); Sparse (1); None (2) \\
\hline 31 & Relative length of sepals and receptacle & Longer (0); Same length (1); Shorter (2) \\
\hline 32 & Peduncle habit & Upright (0); Drooping (1);Weeping (2) \\
\hline 33 & Peduncle color & Green (0); Reddish green (1); Red-purple (2) \\
\hline 34 & Peduncle pubescence & Dense (0); Sparse (1); None (2) \\
\hline 35 & Peduncle length & Assessed in $\mathrm{mm}$ \\
\hline 36 & Peduncle thickness & Assessed in $\mathrm{mm}$ \\
\hline 37 & Pistil number per flower & Counted \\
\hline 38 & Style color & Light green (0); Yellow green (1); Light red-purple (2); Deep red-purple (3) \\
\hline 39 & Style base with pubescence & No (0); Yes (1) \\
\hline 40 & Stamen number per flower & Counted \\
\hline 41 & Anther with red-purple membrane & No (0); Yes (1) \\
\hline 42 & Anther color & White (0); Light yellow (1); Yellow (2); Orange (3) \\
\hline 43 & Filament color & White (0); Light red-purple (1); Deep red-purple (2) \\
\hline 44 & Relative position of stigmas and anthers & Below (0); Same level (1); Above (2) \\
\hline
\end{tabular}

Qualitative traits were directly observed in the field, and the final values of quantitative traits were calculated as the mean value of 30 replicates. Hierarchical number coding system was applied for the qualitative traits following the order from ancestral to evolutionary as far as possible. Consecutively arranged non-negative integers $0,1,2,3, \ldots$, were taken for expression. The dimorphic traits with an evolutionary relationship that was difficult to determine were generally coded as 1 (Yes) and 0 (No). No coding was applied for the quantitative traits and the mean values of the 30 replicates were directly used for further analysis 


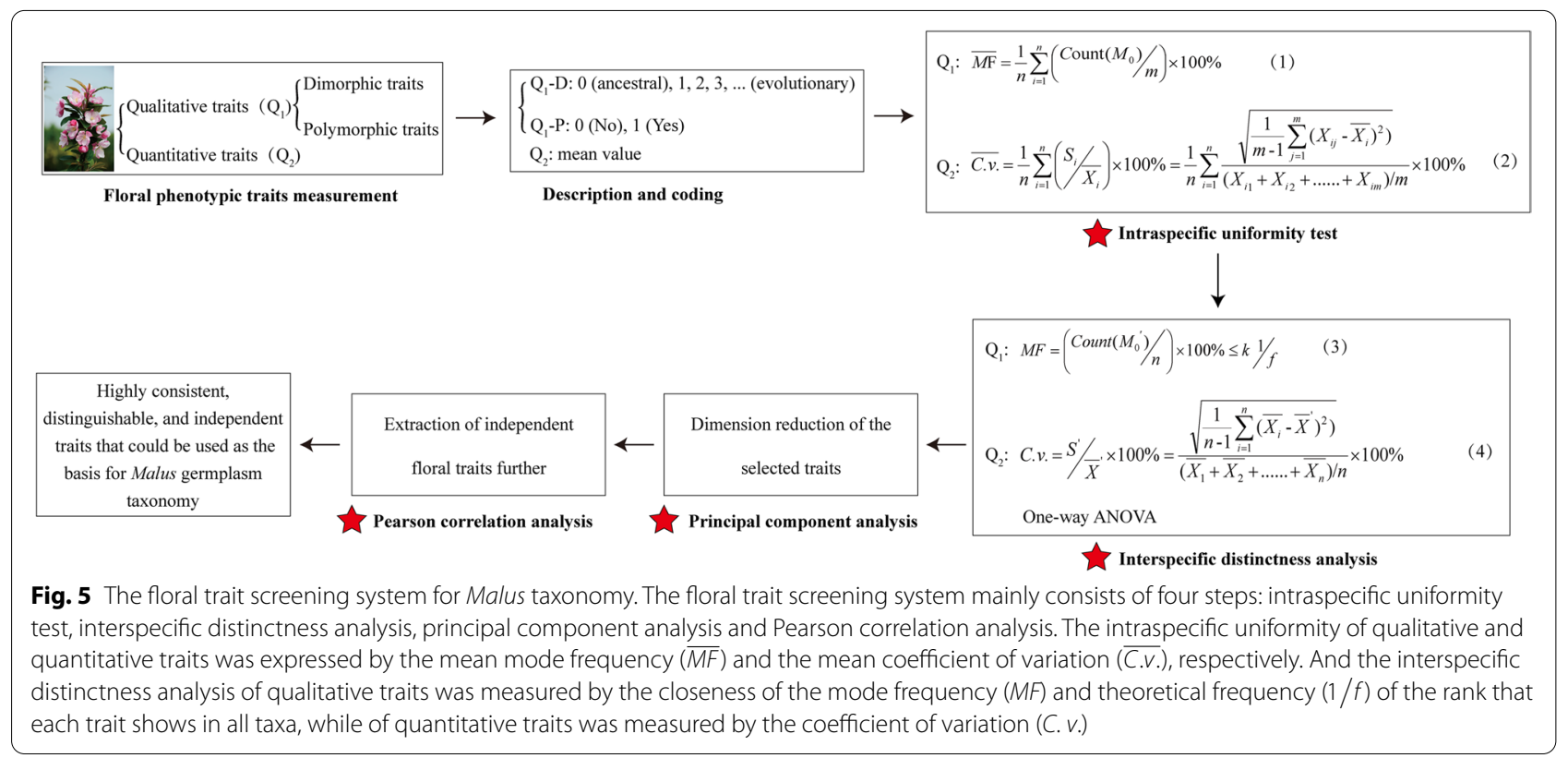

\section{Interspecific distinctness analysis}

The interspecific distinctness analysis of qualitative traits is simply measured by the closeness of the mode frequency $(M F)$ and theoretical frequency $(1 / f)$ of the rank that each trait shows in all taxa. If $M F \leq k 1 / f$, the qualitative trait is more differentiated among all taxa. For quantitative traits, it is expressed by the coefficient of variation $(C . v$.) of the mean value of each trait in all taxa. If C. $v . \geq 15 \%$, it was considered that the differentiation degree of this trait is high among all the taxa. Oneway ANOVA (Tukey's method) should be performed on quantitative traits as well.

$$
\begin{aligned}
& M F=\left(\operatorname{Count}\left(M_{0}{ }^{\prime}\right) / n\right) \times 100 \% \leq k 1 / f \\
& \text { C.v. }=S^{\prime} / \bar{X}^{\prime} \times 100 \%=\frac{\sqrt{\left.\frac{1}{n-1} \sum_{i=1}^{n}\left(\overline{X_{i}}-\bar{X}^{\prime}\right)^{2}\right)}}{\left(\overline{X_{1}}+\overline{X_{2}}+\ldots \cdots+\overline{X_{n}}\right) / n} \times 100 \%
\end{aligned}
$$

where, $M_{0}{ }^{\prime}$ denotes the rank of each trait that appears the most in all taxa; $k$ is a coefficient that depends on the number of ranks $(f)$ of each trait appeared in all taxa; $S$ and $\bar{X}^{\prime}$, respectively, denote the standard deviation and the average of observed mean values of each trait in all taxa.

\section{Principal component analysis and Pearson correlation analysis}

On the premise of higher uniformity and distinctness, principal component analysis (PCA) and Pearson correlation analysis were used to further reduce the dimensionality of the selected traits. In order to eliminate the impact of different dimensions on data analysis, the standard deviation (STD) normalization process was performed in advance on the original numerical matrix; that is, the orthonormal process.

\section{Cluster analysis and ancestor-inclined distribution characteristics of Malus taxa}

Based on the extracted taxonomic traits that could reflect the phenotypes of floral organs, the 142 taxa were quantitatively classified using flexible average method so as to reveal the phenotypic diversity of Malus floral organs. And meanwhile, the ancestor-inclined distribution characteristics was analyzed from two aspects: species and cultivars, aiming at clarifying Malus floral variation taxonomic significance.

\section{Data processing}

Origin 9.0, DPS 9.5, R 3.6.1, and Adobe Illustrator CS5 were used for data processing and graph plotting.

\section{Acknowledgements}

We would like to thank anonymous reviewers for their critical reading, stimulating discussions and helpful comments and suggestions, which allowed us to improve the quality of this manuscript.

\section{Authors' contributions}

TZ designed the experiment. TZ, KN, HC, and JB performed the experiment. $\mathrm{TZ}, \mathrm{KN}$, and WZ analyzed the data and wrote the manuscript. TZ, WZ, XL, DZ, and YE-K revised the manuscript. All authors read and approved the final manuscript. 


\section{Funding}

The study was funded by the Yangzhou Science and Technology Planning Project - Modern Agriculture (YZ2019037), and Key Research and Development Program of Modern Agriculture in Jiangsu Province (BE2019389).

\section{Availability of data and materials}

A total of 142 Malus spp. germplasms (including 31 species and 111 cultivars) were collected from the National Repository of Malus spp. Germplasm (Yangzhou City, Jiangsu Province, China). The datasets used and analysed during the current study could be available from the corresponding author on reasonable request.

\section{Declarations}

\section{Ethics approval and consent to participate}

Not applicable.

\section{Consent for publication}

Not applicable.

\section{Competing interests}

The authors declare that they have no competing interests.

\section{Author details}

${ }^{1}$ Jiangsu Key Laboratory for the Research and Utilization of Plant Resources, Institute of Botany, Jiangsu Province and Chinese Academy of Sciences (Nanjing Botanical Garden Mem. Sun Yat-Sen), Nanjing 210014, China. ${ }^{2}$ College of Horticulture, Jinling Institute of Technology, Nanjing City, Jiangsu Province 210038, P.R. China. ${ }^{3}$ College of Forestry, Nanjing Forestry University, Nanjing 210037, China. ${ }^{4}$ Department of Horticulture, University of Georgia, Athens, GA 30602, USA. ${ }^{5}$ Department of Forest and Conservation Sciences, Faculty of Forestry, University of British Columbia, Vancouver, BC, Canada. ${ }^{6}$ Jiangsu Yufeng Tourism Development Co. Ltd., Yancheng 224000, China.

\section{Received: 14 July 2021 Accepted: 22 September 2021}

\section{Published online: 30 October 2021}

\section{References}

1. Wyman D. Trees for American gardens. New York: Macmillan; 1955.

2. Höfer M, Mams EA, Sellmann J, Peil A. Phenotypic evaluation and characterization of a collection of Malus species. Genet Resour Crop Evol. 2014:61:943-64

3. Lisandru TT, Füstös A, Dumitraş A, Mitre V. Flower development of ornamental crabapple according to BBCH scale. Bull UASVM Hortic. 2017;74:147-8.

4. Muzher BM, Younis RAA, El-Halabi O, Ismail OM. Genetic identification of some Syrian local apple (Malus sp.) cultivars using molecular markers. Res J Agric Biol Sci. 2007;3:704-13.

5. Ulukan $\mathrm{H}$. The evolution of cultivated plant species: classical plant breeding versus genetic engineering. Plant Syst Evol. 2009;280:133-42.

6. Brown SK. Apple (Malus $\times$ domestica). New York: Springer; 2012.

7. Mratinić E, Akšić MF. Phenotypic diversity of apple (Malus sp.) germplasm in South Serbia. Braz Arch Biol Technol. 2012;55:349-58.

8. Fiala JL. Flowering crabapples: the genus Malus. Portland:Timber Press; 1994.

9. Jefferson RM. History, progeny, and locations of crabapples of documented authentic origin. Washington, D.C: U.S. Department of Agriculture; 1970.

10. Zheng Y, Qu XL, Guo L, Sun FY, Mao ZQ, Shen X. Advances on flowering crabapple resources. J Shandong Agric Univ Nat Sci Ed. 2008:39:152-60.

11. Joneghani VN. Pollen morphology of the genus Malus (Rosaceae). Iran J Sci Technol Trans A Sci. 2008;32:89-97.

12. Guo L, Zhou SL, Zhang ZS, Shen X, Cao Y, Zhang DL, et al. Relationships of species, hybrid species and cultivars in genus Malus revealed by AFLP markers. Sci Silvae Sin. 2009;45:33-40.

13. Craene LPRD. Floral diagrams: an aid to understanding flower morphology and evolution. Cambridge: Cambridge University Press; 2010.
14. Wessinger CA, Hileman LC. Accessibility, constraint, and repetition in adaptive floral evolution. Dev Biol. 2016;419:175-83.

15. Endress PK. Flower structure and trends of evolution in eudicots and their major subclades. Ann Mo Bot Gard. 2010;97:541-83.

16. Oliveira EJD, Dias NLP, Dantas JLL. Selection of morpho-agronomic descriptors for characterization of papaya cultivars. Euphytica. 2012:185:253-65.

17. Khadivi-Khuband A, Anjam K. Morphological characterization of Prunus scoparia using multivariate analysis. Plant Syst Evol. 2014:300:1361-72.

18. Osuji JO, Okoli BE, Vuylsteke D, Ortiz R. Multivariate pattern of quantitative trait variation in triploid banana and plantain cultivars. Sci Hortic. 1997;71:197-202.

19. Shaiju PN, Omanakumari N. Floral morphology and systematics of the genus Thottea Rottb. (Aristolochiaceae) from the Western Ghats, India. Plant Syst Evol. 2010;288:213-25.

20. Du F, Li XT, Xu XJ, Yuan Y, Chang L, Zhang XY. Study on the genetic diversity and classification analysis of Liliun cultivars. J Shanxi Agric Univ. 2018;38:16-22.

21. Tang MS, Yang YP, Cai QZ, Xu QR. The diversity of pistillate flowers and its taxonomic value to the classification of Daphniphyllum (Daphniphyllaceae). Bot Stud. 2012;53:509-24.

22. Kim SJ, Lee CH, Kim J, Kim KS. Phylogenetic analysis of Korean native Chrysanthemum species based on morphological characteristics. Sci Hortic. 2014;175:278-89.

23. Nardin CF, Bernacci LC, Plotze RO, Bruno OM, Shepherd GJ. Recognition and differentiation of species in the Passiflora sidifolia complex. Botany. 2015:26:150828143319008.

24. Gao X, LvT, Zang FQ, Lv YM. Classification of the Tulipa gesneriana L. common varieties in Beijing by numerical taxonomy. Mol Breed. 2017; 15:2863-73

25. Xu JJ, Zhao B, Shen HF, Liu XM, Gao XN. Leaf anatomical structures and numerical classification of 15 azalea cultivars. J Northwest For Univ. 2017:32:142-9.

26. Xiao F, Wang XH, Wang YQ, Liu CL, Xie LS, Ren XY. Numerical classification and principal component analysis of 27 Hibiscus syriacus cultivars. J Cent South Univ For Technol. 2019:39:59-64.

27. Kumar C, Singh SK, Pramanik KK, Verma MK, Srivastav M, Singh R, et al. Morphological and biochemical diversity among the Malus species including indigenous Himalayan wild apples. Sci Hortic. 2018;233:204-19.

28. Rehder A. Manual of cultivated trees and shrubs. New York: Macmillam Co; 1940

29. Yu DJ, Yan ZL. Malus in China. J Plant Taxon. 1956:52:77-100.

30. Li YN. Researches of germplasm resources of Malus mill. Beijing: China Agriculture Press; 2001

31. Bemer M, Angenent GC. Floral organ initiation and development. In: Pua EC, Davey MR, editors. Plant developmental biology - biotechnological perspectives. Berlin, Heidelberg: Springer; 2010. p. 173-94.

32. Becker A, Alix K, Damerval C. The evolution of flower development: current understanding and future challenges. Ann Bot. 2011;107:1427-31.

33. Glover BJ, Airoldi CA, Brockington SF, Fernández-Mazuecos M, MartínezPérez C, Mellers G, et al. How have advances in comparative floral development influenced our understanding of floral evolution? Int J Plant Sci. 2015:176:307-23.

34. Endress PK. Evolutionary diversification of the flowers in angiosperms. Am J Bot. 2011:98:370-96.

35. Reyes E, Sauquet H, Nadot S. Perianth symmetry changed at least 199 times in angiosperm evolution. Taxon. 2016;65:945-64.

36. Liu ZQ, Tang GG. Study of the numerical classification on Malus halliana cultivars. Sichuan For Explor Des. 2006;36:377-84.

37. Luo JJ, Bai BB, Li H, Yu HQ You J. Cultivars investigation and numerical classification of ornamental Malus spp. in Beijing. Chin Agric Sci Bull. 2012;28:290-6.

38. Armbruster WS. Evolution of floral form: electrostatic forces, pollination, and adaptive compromise. New Phytol. 2010;152:181-3.

39. Toleno DM, Durbin ML, Lundy KE, Clegg MT. Extensive evolutionary rate variation in floral color determining genes in the genus Ipomoea. Plant Spec Biol. 2010;25:30-42.

40. Nagano Y, Abe K, Kitazawa T, Hattori M, Hirao AS, Itino T. Changes in pollinator fauna affect altitudinal variation of floral size in a bumblebeepollinated herb. Ecol Evol. 2014:4:3395-407. 
41. Agren J, Hellstrom F, Torang P, Ehrlen J. Mutualists and antagonists drive among-population variation in selection and evolution of floral display in a perennial herb. Proc Natl Acad Sci. 2013;110:18202-7.

42. Linhart YB, Grant MC. Evolutionary significance of local genetic differentiation in plants. Annu Rev Ecol Syst. 1996;27:237-77.

43. Stebbins GL. Vatiation and evolution in plant. New York: Columbia University Press; 1950.

44. Rijpkema AS, Vandenbussche M, Koes R, Heijmans K, Gerats T. Variations on a theme: changes in the floral ABCs in angiosperms. Semin Cell Dev Biol. 2010;21:100-7.

45. Endress PK, Doyle JA. Ancestral traits and specializations in the flowers of the basal grade of living angiosperms. Taxon. 2015;64:1093-116.

46. Offord CA. Floral- and leaf-character variation in waratah (Telopea speciosissima, family Proteaceae), with reference to conservation and horticultural improvement. Aust J Bot. 2007;55:684-91.

47. Feng $\sqcup$, Yuan $Z H$, Yin $Y L$, Zhao XQ, Wang XH, Zhang CA, et al. Study on genetic diversity of phenotype traits of different dahlia flower type populations. Shandong Agric Sci. 2010;7:12-6.

48. Tunbridge ND, Sears C, Elle E. Variation in floral morphology and ploidy among populations of Collinsia parviflora, and Collinsia grandiflora. Botany. 2011:89:19-33.

49. Zhou T, Fan JJ, Zhao MM, Zhang DL, Li QH, Wang GB, et al. Phenotypic variation of floral organs in Malus using frequency distribution functions. BMC Plant Biol. 2019;19:574.

50. Zhou T, Zhang WX, Zhang DL, El-Kassaby YA, Fan JJ, Jiang H, et al. A binary-based matrix model for Malus corolla symmetry and its variational significance. Front Plant Sci. 2020;11:416.

51. Langenfel'D VT. Apple: morphological evolution, phylogeny, geography, systematics. Riga: Zinatne; 1991.
52. Shan HY, Cheng J, Zhang R, Yao X, Kong HZ. Developmental mechanisms involved in the diversification of flowers. Nat Plants. 2019;5:917-23.

53. Krizek BA, Anderson JT. Control of flower size. J Exp Bot. 2013;64:1427-37.

54. Borghi M, Fernie AR, Schiestl FP, Bouwmeester HJ. The sexual advantage of looking, smelling, and tasting good: the metabolic network that produces signals for pollinators. Trends Plant Sci. 2017;22:338-50.

55. Endress PK, Matthews ML. Elaborate petals and staminodes in eudicots: diversity, function, and evolution. Org Divers Evol. 2006;6:257-93.

56. Jin XF. Taxonomic study on Rhododendron subgen. Tsutsusi sensu Sleumer (Ericaceae). Ph.D. Dissertation. Zhejiang: Zhejiang University; 2006.

57. UPOV. 2003. Guidelines for the conduct of tests for distinctness, uniformity and stability [ornamental apple(Malus Mill.)]. TG/192/1.

58. UPOV. 2002. General introduction to the guidelines for the conduct of tests for distinctness, homogeneity and stability of new varieties of plants. TG/1/3.

59. Dai SL, Chen JY. A cladistic study on some Dendranthema spp. in China. J Wuhan Bot Res. 1995;15:27-34.

60. Chu AX. Classification of ornamental crabapples in Henan. Ph.D. Dissertation. Nanjing: Nanjing forestry University; 2009.

\section{Publisher's Note}

Springer Nature remains neutral with regard to jurisdictional claims in published maps and institutional affiliations.
Ready to submit your research? Choose BMC and benefit from:

- fast, convenient online submission

- thorough peer review by experienced researchers in your field

- rapid publication on acceptance

- support for research data, including large and complex data types

- gold Open Access which fosters wider collaboration and increased citations

- maximum visibility for your research: over 100M website views per year

At BMC, research is always in progress.

Learn more biomedcentral.com/submissions 